PEREIRA RB; CARVALHO ADF; PINHEIRO JB; SILVA GO; VIEIRA JV. 2015. Avaliação de híbridos experimentais de cenoura no Distrito Federal. Horticultura Brasileira 33: 000-000. DOI - http://dx.doi.org/10.1590/S0102-053620150000100006

\title{
Avaliação de híbridos experimentais de cenoura no Distrito Federal
}

\author{
Ricardo B Pereira; Agnaldo DF Carvalho; Jadir B Pinheiro; Giovani O Silva; Jairo V Vieira \\ Embrapa Hortaliças, C. Postal 218, 70351-970 Brasília-DF; ricardo-borges.pereira@embrapa.br; agnaldo.carvalho@embrapa.br; jadir. \\ pinheiro@embrapa.br; giovani.olegario@embrapa.br; jairo.vidal@embrapa.br
}

\section{RESUMO}

O objetivo deste trabalho foi avaliar o potencial agronômico de 24 híbridos de cenoura, sendo nove obtidos pelo cruzamento entre linhagens de origem tropical (grupo Brasília: CNPH-520 e CNPH536) e temperada (macho-estéreis: CNPH-610, CNPH-664, CNPH633, CNPH-712 e CNPH-671) e 15 obtidos do cruzamento entre linhagens de origem tropical (CNPH-1 a CNPH-15) e a linhagem macho-estéril CNPH-612. Entre 2011 e 2012 foram realizados dois experimentos em blocos casualizados com três repetições, em que a parcela experimental consistiu de três fileiras duplas espaçadas por 20 $\mathrm{cm}$, com $10 \mathrm{~cm}$ entre linhas. A queima-das-folhas ocorreu de forma natural no campo e foi avaliada 90 dias após a semeadura. Os rendimentos agronômicos foram avaliados 100 dias após a semeadura. No primeiro experimento os híbridos $\mathrm{CNPH}-610 \times \mathrm{CNPH}-536$, CNPH$712 \times \mathrm{CNPH}-536$ e CNPH-610 $\times \mathrm{CNPH}-520$ apresentaram menores severidades da doença, enquanto CNPH-610×CNPH-520 e os híbridos CNPH-664 $\times$ CNPH-520 e CNPH-671 $\times$ CNPH-520 apresentaram as maiores produções de raízes comerciais e menores produções de raízes refugo. Os híbridos não diferiram entre si em relação ao peso e comprimento médio de raízes. No segundo experimento, os híbridos CNPH-612 $\times$ CNPH-2, CNPH-612 $\times$ CNPH-6, CNPH-612 $\times$ CNPH-10 e $\mathrm{CNPH}-612 \times \mathrm{CNPH}-11$ apresentaram resultados superiores para todas as características avaliadas (resistência à queima-das-folhas, produção de raízes comerciais e refugo, peso, comprimento e diâmetro médio de raízes), seguidos de CNPH-612×CNPH-3, que apresentou inferior comprimento médio de raízes.

Palavras-chave: Daucus carota, linhagem, queima-das-folhas, divergência genética.

\section{ABSTRACT \\ Evaluation of carrot experimental hybrids in the Federal District, Brazil}

The aim of this study was to evaluate the agronomic potential of 24 carrot hybrids, nine being obtained by crossings between lines of tropical origin (Brasília group: CNPH-520 and CNPH536) and temperate origin (male-sterile: CNPH-610, CNPH-664, CNPH-633, CNPH-712 and CNPH-671) and 15 lines obtained from crossings between tropical origin lines (CNPH-1 to CNPH-15) and the male-sterile line CNPH-612. Between 2011 and 2012 two experiments were carried out in randomized complete block design with three replications. The experimental plots consisted of three double rows spaced $20 \mathrm{~cm}$ apart, with $10 \mathrm{~cm}$ between rows. The leaf blight occurred naturally in the field and was assessed 90 days after sowing. The agronomic yields were evaluated 100 days after sowing. In the first experiment, the hybrids CNPH-610 $\times$ CNPH-536, $\mathrm{CNPH}-712 \times \mathrm{CNPH}-536$ and $\mathrm{CNPH}-610 \times \mathrm{CNPH}-520$ presented lower disease severity while $\mathrm{CNPH}-610 \times \mathrm{CNPH}-520$ and the hybrids CNPH-664 $\times$ CNPH-520 and CNPH- $671 \times$ CNPH-520 showed the highest yields of marketable roots and lower production of refused roots. Hybrids did not differ in average weight and length of roots. In the second experiment, the hybrids CNPH- $612 \times \mathrm{CNPH}-2, \mathrm{CNPH}-$ $612 \times \mathrm{CNPH}-6$, CNPH-612 $\times$ CNPH-10 and CNPH-612 $\times$ CNPH- 11 presented better results for all traits (resistance to leaf blight, marketable root production and refuse, weight, length and diameter of roots), followed by CNPH-612×CNPH-3, which presented lower average length of roots.

Keywords: Daucus carota, lines, leaf blight, genetic divergence.

(Recebido para publicação em 3 de julho de 2013; aceito em 9 de setembro de 2014) (Received on July 3, 2013; accepted on September 9, 2014)

\begin{abstract}
A cenoura (Daucus carota) apresenta ampla versatilidade culinária e adaptabilidade a diferentes condições de cultivo, tornando-se uma das hortaliças mais cultivadas no mundo e a quinta hortaliça mais consumida no Brasil, além de possuir elevado valor nutritivo e ser uma das melhores fontes de $\beta$-caroteno (provitamina A) (Zeraik \& Yariwake, 2008). Segundo estimativas, no Brasil, em 2011, foram cultivados aproximadamente 25,28 mil hectares com cenoura, o que resultou numa produção de 760,9 mil toneladas
\end{abstract}

(Anuário..., 2012).

Nos últimos 10 anos tem ocorrido de forma intensa e irreversível a substituição de cultivares de polinização livre por híbridos (Vieira et al., 2012). Tal fato atribuiu-se principalmente a algumas vantagens que estas possuem em relação às cultivares de polinização aberta, como produtividade e uniformidade de raízes. Segundo dados da Associação Brasileira do Comércio e Mudas, 62\% da área de cenoura cultivada de inverno e $38 \%$ cultivada no verão, no ano de 2009, utilizaram sementes híbridas
(ABCSEM, 2009). Diante desta tendência, os programas de melhoramento genético de cenouras de empresas públicas, como a Embrapa, que inicialmente trabalhavam no desenvolvimento de cultivares de polinização aberta iniciaram programas visando também à obtenção de sementes híbridas de cenoura.

Para a obtenção de híbridos de cenoura utilizam-se linhagens macho-estéreis; no caso, os mais utilizados são o petalóide e o Brown (antera marrom). Para a síntese de um híbrido $\mathrm{F}_{1}$ são necessárias três linhagens, designadas de 
A, B e C. A linhagem A é a linhagem macho-estéril genitora feminina do híbrido $\mathrm{F}_{1}$. A linhagem $\mathrm{B}$ é mantenedora de A, ou seja, uma linhagem isogênica de A, com apenas a diferença de possuir fertilidade condicionada por genes citoplasmáticos. A linhagem $\mathrm{C}$ é a genitora masculina do híbrido $\mathrm{F}_{1}$. Esta deve ser fértil, mas a fertilidade pode ser condicionada por alelos citoplasmáticos, nucleares ou por ambos (Peterson \& Simon, 1986).

$\mathrm{Na}$ exploração de híbridos de qualquer espécie, os fatores envolvidos na manifestação da heterose são a divergência genética e os efeitos de dominância diferentes de zero (Falconer \& Mackay, 1996). Na literatura os trabalhos relatando correlação positiva e significativa entre diversidade genética e heterose são controversos (Paterniani et al., 2008). Alguns mostram correlação entre diversidade e heterose (Maluf et al., 1983; Oliveira et al., 1998; Oliveira et al., 2004) enquanto outros apresentam resultados conflitantes (Miranda et al., 1988; Paterniani et al., 2008).

Nos Estados Unidos os primeiros híbridos comerciais foram disponibilizados no início da década de 60 e, desde então, centenas de novas combinações híbridas foram lançadas, e nessa federação, atualmente, praticamente 100\% da área de cultivo da cenoura utilizam combinações híbridas (Peterson \& Simon, 1986). No Brasil, os trabalhos com avaliação de híbridos experimentais de cenoura são escassos. Em Minas Gerais, Lima Júnior et al. (2012) estudaram o comportamento da cultivar de polinização livre Nantes com o híbrido Nayarit, duas cultivares recomendadas para plantio de inverno, com seis níveis críticos de tensão da água no solo. Os autores verificaram produtividades superiores para peso total e comercial de raízes em qualquer tensão e, além disso, relatam a superioridade do híbrido Nayarit na eficiência do uso da água. Esses resultados explicam o porquê do aumento de áreas cultivadas com sementes híbridas no inverno em 2009, anteriormente publicado pela Associação Brasileira do Comércio de Sementes e Mudas (ABCSEM, 2009), com base nos dados sobre comercialização de sementes.
Durante o cultivo de verão, o fator considerado mais limitante para a produção de cenoura é ocorrência de doenças, como a queima-das-folhas. Trata-se de um complexo causado por dois fungos, Alternaria dauci e Cercospora carotae, e uma bactéria, Xanthomonas campestris pv. carotae. Estes patógenos podem ser encontrados em infecções múltiplas ou não na mesma estação de cultivo, planta, ou lesão, dependendo da região, ano e manejo da cultura (Pereira et al., 2012). Esta doença ocorre sobre as folhas principalmente nos período de altas precipitações e temperaturas elevadas, podendo danificar drasticamente a área foliar e prejudicar o crescimento das raízes, as quais não atingem os padrões comerciais (Henz \& Lopes, 2000).

Diante do exposto o presente trabalho teve por objetivo avaliar o potencial agronômico de dois conjuntos de híbridos, um obtido de cruzamentos entre linhagens oriundas de populações divergentes (de origem tropical e temperada) e outro de cruzamentos entre linhagens oriundas de populações do grupo Brasília (de origem tropical).

\section{MATERIAL E MÉTODOS}

Durante os meses de novembro de 2011 a março de 2012 foram realizados dois experimentos em campo da Embrapa Hortaliças, Brasília-DF, em áreas próximas. No primeiro foram avaliados híbridos experimentais de cenoura derivados do cruzamento de cinco linhagens femininas derivadas de populações provenientes de clima temperado (macho-estéreis) (CNPH-610, CNPH-664, CNPH-633, CNPH-712 e CNPH-671) com linhagens provenientes de populações do grupo Brasília (férteis) CNPH-520 e CNPH-536, em esquema de dialelo parcial $5 \times 2$, obtendo todas as combinações, exceto o híbrido CNPH$671 \times$ CNPH-536. Como testemunhas foram utilizadas as cultivares comerciais Juliana (híbrido) e BRS Planalto (cultivar de polinização aberta). Já no segundo experimento foram avaliados 15 híbridos experimentais de cenoura derivados do cruzamento de 15 linhagens de verão oriundas de populações de origem tropical do grupo Brasília
(CNPH-1 a CNPH-15) com a linhagem macho-estéril de origem tropical CNPH612. Como testemunhas foram utilizadas as cultivares comerciais Brasília, BRS Planalto e Juliana.

Para o plantio da cenoura o solo foi convencionalmente preparado com aração e gradagem. Em seguida foram suspensos canteiros de 1,0 m de largura e 20 $\mathrm{cm}$ de altura, os quais foram adubados a lanço com $1.200 \mathrm{~kg} / \mathrm{ha}$ do formulado comercial 04-14-08. Para a incorporação do adubo nos canteiros utilizou-se um roto-encanteirador. No dia 22 de novembro realizou-se a semeadura dos genótipos, e 35 dias após realizou-se o desbaste das plantas, deixando espaçamentos de 4 a $5 \mathrm{~cm}$ entre plantas. Estas foram irrigadas por aspersão conforme a necessidade durante todo o período experimental. Não houve aplicação de agroquímicos nos experimentos para controle de pragas ou doenças.

Os experimentos foram realizados em delineamento de blocos casualizados com três repetições. No primeiro as parcelas constituíram-se de dez fileiras duplas no sentido transversal do canteiro, onde o espaçamento entre fileiras foi de $20 \mathrm{~cm}$ e dentro das fileiras de 10 $\mathrm{cm}$ (área total de $3,3 \mathrm{~m}^{2}$ ), enquanto no segundo as parcelas constituíram-se de sete fileiras duplas no sentido transversal do canteiro, onde o espaçamento entre fileiras foi de $20 \mathrm{~cm}$ e dentro das fileiras de $10 \mathrm{~cm}$ (área total de 2,31 $\mathrm{m}^{2}$ ).

A infecção pela queima-das-folhas ocorreu de forma natural, sem inoculação. Os níveis naturais de inóculo foram considerados adequados pela severidade e uniformidade da infecção observada em algumas parcelas. A severidade da queima-das-folhas foi avaliada 90 dias após a semeadura. Foram atribuídas notas de 1 a 5 para as parcelas, onde a nota 1 correspondeu a $>90 \%$ de severidade, nota 2 de 50 a $90 \%$ de severidade, nota 3 de 12,5 a $50 \%$ de severidade, nota 4 de 3,8 a $12,55 \%$ de severidade e nota 5 correspondeu a $<3,8 \%$ de severidade. Em seguida, as notas foram transformadas para severidade.

Cem dias após a semeadura realizou-se a avaliação do peso de raízes refugos (PRR), peso de raízes comerciais (PRC), peso médio de raiz (PMR), comprimento médio de raiz (CMR) e diâmetro médio 
de raiz (DMR). Os dados de produção foram calculados e apresentados em $\mathrm{t}$ / ha.

As análises estatísticas dos dados foram realizadas no programa estatístico Genes v. 2006.4.1 (Cruz, 2006), e as médias agrupadas pelo teste de Scott-Knott $(\mathrm{p} \leq 0,05)$.

\section{RESULTADOS E DISCUSSÃO}

Com relação ao primeiro experimento, os híbridos CNPH-610×CNPH-536, CNPH-610 $\times$ CNPH-520 e CNPH$712 \times \mathrm{CNPH}-536$ apresentaram severidades da queima-das-folhas semelhantes pelo teste de Scott-Knott $(\mathrm{p} \leq 0,05)$ e inferiores a $8,20 \%$, sendo os genótipos mais tolerantes dentre os avaliados (Figura 1). No segundo grupo de genótipos mais tolerantes estiveram o híbrido CNPH-664×CNPH-520 e a cultivar BRS Planalto, que apresentaram severidades de 21,94 e 18,75\%, respectivamente. A cultivar Juliana e os híbridos CNPH-664×CNPH-536, $\mathrm{CNPH}-712 \times \mathrm{CNPH}-520$ e CNPH$671 \times \mathrm{CNPH}-520$ permaneceram no terceiro grupo pelo teste de Scott-Knott $(\mathrm{p} \leq 0,05)$ e apresentaram severidades intermediárias e semelhantes, de 30,14 a $31,25 \%$. Já os híbridos CNPH-633×CNPH-536 e CNPH$633 \times \mathrm{CNPH}-520$ apresentaram as maiores severidades, 47,33 e 70,00\% e, respectivamente, estando no grupo das mais suscetíveis. Esse resultado evidencia a variabilidade genética entre essas linhagens de origem de clima temperado e tropical, ou seja, geraram combinações híbridas superiores, semelhantes e inferiores à testemunha BRS Planalto, uma cultivar altamente tolerante à queima-das-folhas (Embrapa, 2012).

A produção de raízes comerciais dos híbridos CNPH-610×CNPH-520, CNPH-664×CNPH-520 e CNPH$671 \times$ CNPH-520, 46,55, 37,14 e 38,75 t/ha, respectivamente, foram superiores aos demais tratamentos pelo teste de Scott-Knott $(\mathrm{p} \leq 0,05)$ (Tabela 1). Junto com o híbrido CNPH$633 \times$ CNPH-520, os híbridos mais produtivos também apresentaram a menor quantidade de raízes refugo pelo teste de Scott-Knott $(\mathrm{p} \leq 0,05)$. Os híbridos CNPH-610×CNPH-536, CNPH-664×CNPH-536, CNPH$712 \times \mathrm{C} \mathrm{N} \mathrm{P} \mathrm{H}-520, \quad \mathrm{CN}$ P H $712 \times$ CNPH-536 e 'BRS Planalto' produziram de 28,89 a $31,97 \mathrm{t}$ /ha de raízes comerciais (segundo grupo), seguidos de $\mathrm{CNPH}-633 \times \mathrm{CNPH}-520 \mathrm{e}$
CNPH-633 $\times$ CNPH-536, com produções de 24,11 e 23,01 t/ha, respectivamente (terceiro grupo), e de Juliana, com produção de 9,50 t/ha (quarto grupo), ou seja, inferior a todos os genótipos avaliados. Apesar da baixa produção dos híbridos em que a linhagem feminina CNPH-633 participou, esses resultados não eliminam os referidos híbridos, uma vez que o baixo desempenho produtivo foi consequência da suscetibilidade a queima-das-folhas que esses materiais apresentaram devido à falta de controle químico da doença. Esse fato se comprova pelo desempenho de 'Juliana', a cultivar menos produtiva nesse experimento, mas amplamente cultivada em regiões que utilizam o controle químico para o manejo desta doença. Embora não quantificada nesse trabalho, chamaram a atenção os atributos como coloração, formato e lisura muito promissores e adequados aos padrões exigidos pelo mercado. Caberia avaliar esses híbridos em sistemas que utilizam o controle químico da queima-das-folhas, em que a queima-das-folhas não seja limitante para a cultura.

Com relação às variáveis peso e comprimento médio de raiz, não houve diferença significativa entre os genótipos avaliados, salvo a cultivar

Tabela 1. Médias do rendimento de híbridos experimentais de cenoura cultivados na safra 2011/2012 \{average (means) yield of experimental carrot hybrids grown in 2011/2012 season \}. Brasília, Embrapa Hortaliças, 2012.

\begin{tabular}{|c|c|c|c|c|c|}
\hline \multirow{2}{*}{ Genótipos } & PRC & PRR & \multirow{2}{*}{ PMR (g) } & CMR & DMR \\
\hline & & & & \multicolumn{2}{|c|}{$(\mathrm{cm})$} \\
\hline CNPH-610×CNPH-520 & $46,55 \mathrm{a}$ & $5,60 \mathrm{~b}$ & $101,64 \mathrm{a}$ & $16,86 \mathrm{a}$ & $2,86 \mathrm{~b}$ \\
\hline CNPH-610×CNPH-536 & $28,89 \mathrm{~b}$ & $13,23 \mathrm{a}$ & 103,96 a & $17,56 \mathrm{a}$ & $2,76 \mathrm{~b}$ \\
\hline CNPH-664×CNPH-520 & $37,14 \mathrm{a}$ & $7,08 \mathrm{~b}$ & $130,05 \mathrm{a}$ & $18,88 \mathrm{a}$ & $3,06 \mathrm{a}$ \\
\hline CNPH-664×CNPH-536 & $30,32 \mathrm{~b}$ & $11,22 \mathrm{a}$ & $95,88 \mathrm{a}$ & $17,06 \mathrm{a}$ & $2,80 \mathrm{~b}$ \\
\hline CNPH-633×CNPH-520 & $24,11 \mathrm{c}$ & $7,81 \mathrm{~b}$ & $100,38 \mathrm{a}$ & $15,52 \mathrm{a}$ & $2,99 \mathrm{a}$ \\
\hline $\mathrm{CNPH}-633 \times \mathrm{CNPH}-536$ & $23,01 \mathrm{c}$ & $12,80 \mathrm{a}$ & $79,32 \mathrm{a}$ & $15,18 \mathrm{a}$ & $2,71 \mathrm{~b}$ \\
\hline CNPH-712×CNPH-520 & $31,65 \mathrm{~b}$ & $11,94 \mathrm{a}$ & $114,44 \mathrm{a}$ & $17,03 \mathrm{a}$ & $3,01 \mathrm{a}$ \\
\hline CNPH-712×CNPH-536 & $31,97 \mathrm{~b}$ & $10,86 \mathrm{a}$ & $102,41 \mathrm{a}$ & $17,97 \mathrm{a}$ & $2,75 \mathrm{~b}$ \\
\hline CNPH-671×CNPH-520 & $38,75 \mathrm{a}$ & $5,31 \mathrm{~b}$ & $107,13 \mathrm{a}$ & $16,22 \mathrm{a}$ & $3,17 \mathrm{a}$ \\
\hline Juliana & $9,50 \mathrm{~d}$ & $10,16 \mathrm{a}$ & $70,11 \mathrm{a}$ & $12,10 \mathrm{~b}$ & $2,81 \mathrm{~b}$ \\
\hline BRS Planalto & $30,14 \mathrm{~b}$ & $9,53 \mathrm{a}$ & $114,02 \mathrm{a}$ & $16,18 \mathrm{a}$ & $3,05 \mathrm{a}$ \\
\hline CV (\%) & 21,40 & 23,23 & 15,71 & 8,09 & 5,84 \\
\hline Médias & 29,45 & 10,73 & 94,59 & 15,72 & 3,15 \\
\hline
\end{tabular}

$\mathrm{PRC}=$ peso de raízes comerciais (weight of marketable roots); $\mathrm{PRR}=$ peso de raízes refugos (weight of refused roots); $\mathrm{PMR}=$ peso médio de raiz (mean weight of roots); $\mathrm{CMR}=$ comprimento médio de raiz (mean root lenght); $\mathrm{DMR}=$ diâmetro médio de raiz (mean root diameter). Médias seguidas de mesma letra não diferem entre si pelo teste de Scott-Knott $(\mathrm{p}<0,05)$ \{average values followed by the same letter are not different by the Scott-Knott test $(\mathrm{p} \leq 0.05)\}$. 


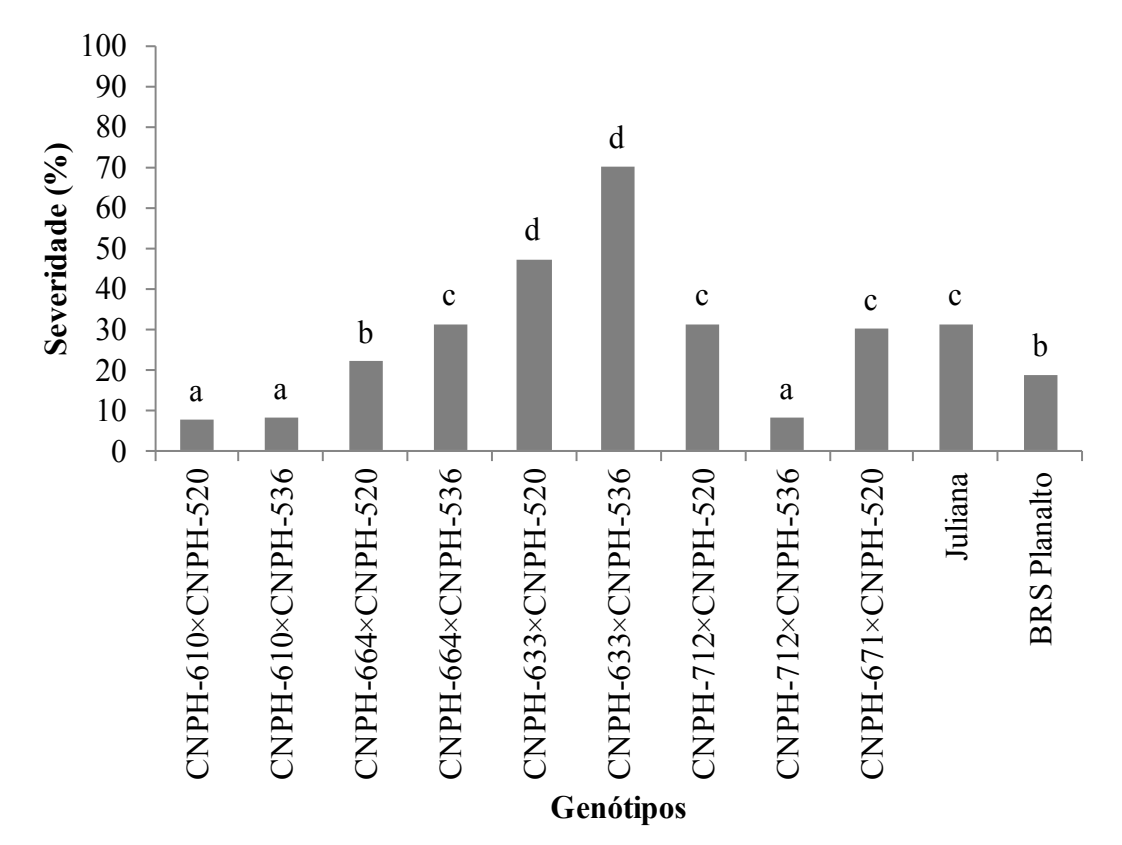

Figura 1. Severidade da queima-das-folhas em híbridos experimentais de cenoura cultivados na safra 2011/2012, 90 dias após semeadura. Médias seguidas de mesma letra não diferem entre si pelo teste de Scott-Knott $(\mathrm{p} \leq 0,05)$ \{severity of leaf blight in experimental hybrids of carrot grown in 2011/2012 season, 90 days after sowing. Averages (means) followed by the same letter are not different by the Scott-Knott test $(\mathrm{p} \leq 0.05)\}$. Brasília, Embrapa Hortaliças, 2012.

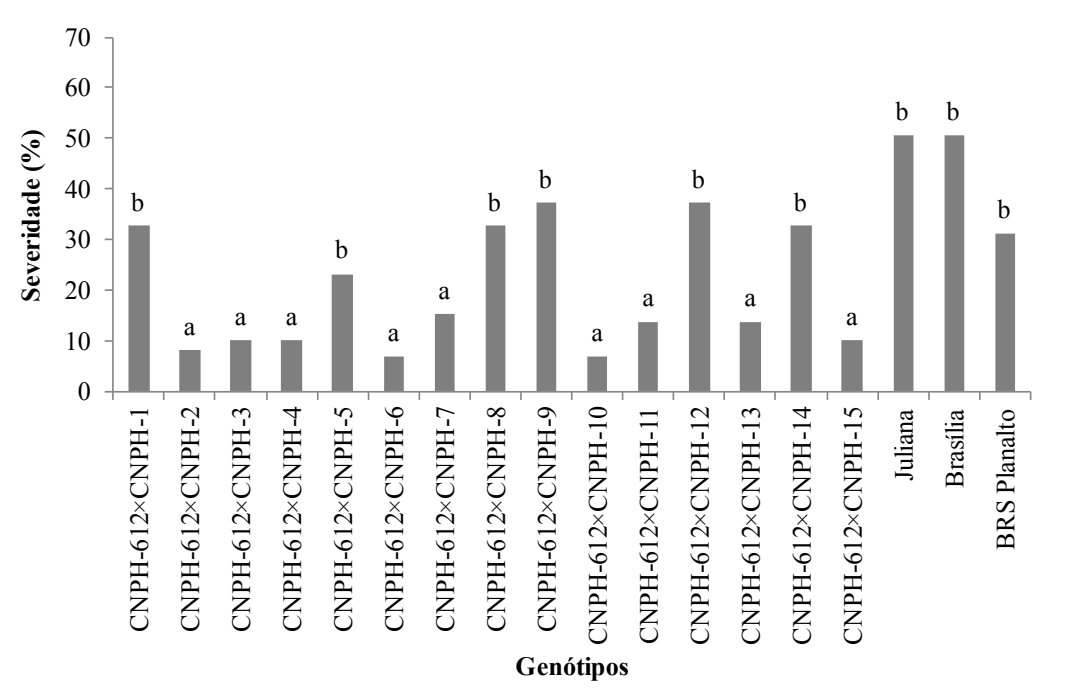

Figura 2. Severidade da queima-das-folhas em híbridos experimentais de cenoura na safra 2011/2012, aos 90 dias após semeadura. Médias seguidas de mesma letra não diferem entre si pelo teste de Scott-Knott $(\mathrm{p} \leq 0,05)$ \{severity of leaf blight in experimental carrot hybrids grown in 2011/2012 season, 90 days after sowing. Averages followed by the same letter are not different by the Scott-Knott test $(\mathrm{p} \leq 0.05)\}$. Brasília, Embrapa Hortaliças, 2012.

Juliana que apresentou comprimento de raiz inferior, provavelmente devido à alta incidência da queima-das-folhas. Os híbridos CNPH-664×CNPH-520, CNPH-633 $\times$ CNPH-520, CNPH$712 \times \mathrm{CN}$ P H $-520, \quad \mathrm{C} \mathrm{N} \mathrm{P} \mathrm{H} \mathrm{-}$ adequados aos padrões comerciais de que o mercado brasileiro exige, como raízes entre 16 e $21 \mathrm{~cm}$ de comprimento e diâmetro aproximado de $3,0 \mathrm{~cm}$.

A cultivar BRS Planalto, obtida por meio do melhoramento genético de populações do grupo Brasília, apresentou maior nível de resistência à doença em relação à cultivar Juliana, indicada para cultivo de verão. Tal comportamento também foi observado por Shibata et al. (2008). De forma geral, os híbridos menos produtivos apresentaram maior severidade da queima-das-folhas, como é o caso dos híbridos CNPH-633×CNPH-520 e CNPH-633 $\times$ CNPH-536 e da testemunha Juliana. Esta menor produtividade é consequência da redução da parte aérea das plantas pelo ataque da doença, que reflete negativamente no tamanho das raízes, que consequentemente não atingem o padrão comercial (Pereira $e t$ al., 2012). Segundo Brito et al. (1997), existe uma correlação negativa alta entre produção de raízes e danos pelo ataque de queima-das-folhas, que no período do verão chega a $-0,77$.

Com relação ao segundo experimento, os híbridos experimentais de verão $\mathrm{CNPH}-612 \times \mathrm{CNPH}-1, \mathrm{CNPH}-$ $612 \times \mathrm{CNPH}-5$, CNPH-612 $\times$ CNPH- 8 , CNPH- $612 \times \mathrm{CNPH}-9$, CNPH $612 \times \mathrm{CNPH}-12$, e CNPH-612 $\times$ CNPH-14 e as cultivares Juliana, Brasília e BRS Planalto apresentaram severidades da queima-das-folhas semelhantes e superiores a $23,2 \%$, grupo das mais suscetíveis pelo teste de Scott-Knott $(\mathrm{p} \leq 0,05)$ (Figura 2), enquanto os demais híbridos apresentaram severidades inferiores a $15,4 \%$, grupo das mais tolerantes pelo teste de Scott-Knott $(\mathrm{p} \leq 0,05)$. Os híbridos CNPH-612×CNPH-2, CNPH$612 \times \mathrm{CNPH}-3$, CNPH-612 $\times$ CNPH- 6 , CNPH-612 $\times$ CNPH-10 e CNPH$612 \times \mathrm{CNPH}-11$ não diferiram entre si e apresentaram as maiores produções de raízes comerciais, acima de $72,7 \mathrm{t} / \mathrm{ha}$, na comparação com os demais híbridos pelo teste Scott-Knott $(\mathrm{p} \leq 0,05)$, com produções de 53,42 a 69,80 t/ha (Tabela 2). As testemunhas Juliana, Brasília e BRS Planalto produziram 17,80, 36,13 e 58,07 t/ha, respectivamente. Os híbridos CNPH- $612 \times \mathrm{CNPH}-3$, CNPH$612 \times \mathrm{CNPH}-6$ e $\mathrm{CNPH}-612 \times \mathrm{CNPH}-10$ 
Tabela 2. Médias do rendimento de híbridos de cenoura cultivados na safra 2011/2012, aos 100 dias após semeadura (mean yields of experimental carrot hybrids grown in 2011/2012 season). Brasília, Embrapa Hortaliças, 2012.

\begin{tabular}{|c|c|c|c|c|c|}
\hline \multirow{2}{*}{ Genótipos } & PRC & PRR & \multirow{2}{*}{$\operatorname{PMR}(\mathrm{g})$} & CMR & DMR \\
\hline & \multicolumn{2}{|c|}{ (t/ha) } & & \multicolumn{2}{|c|}{$(\mathrm{cm})$} \\
\hline CNPH-612×CNPH-1 & $53,42 \mathrm{~b}$ & $8,88 \mathrm{~b}$ & $109,33 \mathrm{a}$ & $18,89 \mathrm{a}$ & $3,04 \mathrm{a}$ \\
\hline CNPH-612 $\times$ CNPH- 2 & 85,01 a & $11,40 \mathrm{~b}$ & $118,83 \mathrm{a}$ & $18,56 \mathrm{a}$ & $3,05 \mathrm{a}$ \\
\hline CNPH-612×CNPH-3 & 83,36 a & $7,04 \mathrm{c}$ & $109,64 \mathrm{a}$ & $17,13 \mathrm{~b}$ & $3,09 \mathrm{a}$ \\
\hline CNPH-612×CNPH-4 & $69,51 \mathrm{~b}$ & $15,97 \mathrm{a}$ & $118,20 \mathrm{a}$ & $18,45 \mathrm{a}$ & $3,12 \mathrm{a}$ \\
\hline CNPH-612×CNPH-5 & $68,01 \mathrm{~b}$ & $17,52 \mathrm{a}$ & $124,41 \mathrm{a}$ & $17,91 \mathrm{~b}$ & $3,20 \mathrm{a}$ \\
\hline CNPH-612×CNPH-6 & $81,94 \mathrm{a}$ & $7,65 \mathrm{c}$ & $133,55 \mathrm{a}$ & $19,29 \mathrm{a}$ & $3,14 \mathrm{a}$ \\
\hline CNPH-612×CNPH-7 & $53,51 \mathrm{~b}$ & $11,38 \mathrm{~b}$ & $105,62 \mathrm{~b}$ & $18,50 \mathrm{a}$ & $2,80 \mathrm{~b}$ \\
\hline CNPH-612×CNPH- 8 & $65,41 \mathrm{~b}$ & $12,20 \mathrm{a}$ & $105,95 \mathrm{~b}$ & $17,54 \mathrm{~b}$ & $2,97 \mathrm{a}$ \\
\hline CNPH-612×CNPH-9 & $62,29 \mathrm{~b}$ & $9,58 \mathrm{~b}$ & $91,87 \mathrm{~b}$ & $17,06 \mathrm{~b}$ & $2,76 \mathrm{~b}$ \\
\hline CNPH-612×CNPH-10 & $72,76 \mathrm{a}$ & $6,42 \mathrm{c}$ & $124,30 \mathrm{a}$ & $19,05 \mathrm{a}$ & $3,13 \mathrm{a}$ \\
\hline CNPH-612×CNPH- 11 & $85,28 \mathrm{a}$ & $9,27 \mathrm{~b}$ & $123,86 \mathrm{a}$ & $19,22 \mathrm{a}$ & $3,08 \mathrm{a}$ \\
\hline CNPH-612×CNPH-12 & $63,80 \mathrm{~b}$ & $9,41 \mathrm{~b}$ & $110,36 \mathrm{a}$ & $18,60 \mathrm{a}$ & $2,94 \mathrm{~b}$ \\
\hline CNPH-612×CNPH-13 & $59,94 \mathrm{~b}$ & $12,99 \mathrm{a}$ & $97,60 \mathrm{~b}$ & $17,76 \mathrm{~b}$ & $2,86 \mathrm{~b}$ \\
\hline CNPH-612×CNPH-14 & $62,08 \mathrm{~b}$ & $10,00 \mathrm{~b}$ & $96,69 \mathrm{~b}$ & $17,52 \mathrm{~b}$ & $2,81 \mathrm{~b}$ \\
\hline CNPH-612×CNPH-15 & $69,80 \mathrm{~b}$ & $8,57 \mathrm{~b}$ & $99,51 \mathrm{~b}$ & $18,70 \mathrm{a}$ & $2,84 \mathrm{~b}$ \\
\hline Juliana & $17,08 \mathrm{~d}$ & $19,82 \mathrm{a}$ & $75,83 \mathrm{c}$ & $13,21 \mathrm{c}$ & $2,85 \mathrm{~b}$ \\
\hline Brasília & $36,13 \mathrm{c}$ & $17,58 \mathrm{a}$ & $95,30 \mathrm{~b}$ & $14,39 \mathrm{c}$ & $3,07 \mathrm{a}$ \\
\hline BRS Planalto & $58,07 \mathrm{~b}$ & $15,28 \mathrm{a}$ & $109,73 \mathrm{a}$ & $17,43 \mathrm{~b}$ & $3,00 \mathrm{a}$ \\
\hline CV (\%) & 11,50 & 2,64 & 9,77 & 4,52 & 5,54 \\
\hline Médias & 63,74 & 11,72 & 108,36 & 17,73 & 2,99 \\
\hline
\end{tabular}

$\mathrm{PRC}=$ peso de raízes comerciais (weight of marketable roots); $\mathrm{PRR}=$ peso de raízes refugos (weight of refused roots); $\mathrm{PMR}=$ peso médio de raiz (mean weight of roots); $\mathrm{CMR}=$ comprimento médio de raiz (mean root lenght); $\mathrm{DMR}=$ diâmetro médio de raiz (mean root diameter). Médias seguidas de mesma letra não diferem entre si pelo teste de Scott-Knott $(\mathrm{p} \leq 0,05)$ \{average values followed by the same letter are not different by the Scott-Knott test $(\mathrm{p} \leq 0.05)\}$.

apresentaram as menores produções de raízes refugos, de 6,42 a 7,65 t/ha, enquanto a média dos demais híbridos foi de 12,66 t/ha. Diante dos resultados, pode-se inferir que a baixa produtividade das cultivares Juliana e Brasília está relacionada à alta severidade da queima-das-folhas. De forma geral, os genótipos com maior produção comercial apresentaram menor produção de raízes refugo (Brito et al., 1997).

Os híbridos CNPH-612 $\times \mathrm{CNPH}-1$, CNPH- $612 \times \mathrm{CNPH}-2, \mathrm{CNPH}-$ $612 \times \mathrm{CNPH}-4$, CNPH-612 $\times$ CNPH- 6 , CNPH-612 $\times$ CNPH- 10 e CNPH$612 \times \mathrm{CNPH}-11$ apresentaram resultados superiores para as características peso médio de raiz (entre 109,3 e 133,6 g), comprimento (entre 18,4 e 19,3 cm) e diâmetro médio de raízes (entre 2,97 e 3,20 cm). Outros híbridos também apresentam resultados semelhantes para algumas destas características, como CNPH-612 $\times$ CNPH-3 e CNPH$612 \times \mathrm{CNPH}-3$ para peso e diâmetro médio de raízes, $\mathrm{CNPH}-612 \times \mathrm{CNPH}-12$ para peso e comprimento médio de raízes, CNPH-612 $\times$ CNPH-7 para comprimento e CNPH- $612 \times \mathrm{CNPH}-8$ para peso médio de raízes. Dentre as testemunhas, BRS Planalto apresentou resultados semelhantes a esses para peso e diâmetro médio de raízes, enquanto Brasília apresentou resultados semelhantes para diâmetro médio de raízes.

Estes resultados evidenciam uma variabilidade genética entre os híbridos experimentais avaliados e permite selecionar combinações hibridas mais favoráveis dentre combinações oriundas dos cruzamentos entre linhagens sintetizadas de uma mesma população de origem tropical. Os híbridos CNPH-612×CNPH-2, CNPH$612 \times \mathrm{CNPH}-6, \mathrm{CNPH}-612 \times \mathrm{CNPH}-10$ e CNPH-612 $\times \mathrm{CNPH}-11$, em especial, apresentaram resultados superiores em todas as características agronômicas avaliadas, sendo considerados os mais promissores. Entretanto, outros apresentaram algumas características componentes de produção superiores às testemunhas, o que também indica resultados promissores.

Comparando o comportamento da testemunha Juliana, um híbrido no qual um dos genitores provavelmente é de origem tropical e outro temperada, com os demais híbridos avaliados nos experimentos, fica evidente que o maior grau de resistência à queima-das-folhas é obtido quando os dois genitores são originários de germoplasma tropical. Enquanto no primeiro experimento Juliana apresentou desempenho intermediário aos demais genótipos, no segundo todos os híbridos experimentais a superaram. Em termos práticos isso significa que, se o foco do programa de melhoramento 
fosse somente desenvolver cultivares altamente resistentes à queima-das-folhas, os híbridos deveriam ser obtidos de genitores masculinos e femininos de origem tropical. Contudo, a seleção de uma cultivar de cenoura não é baseada apenas por um caráter, como resistência a doenças, e sim por um conjunto de características agronômicas, tais como produtividade, qualidade, aparência, entre outras. No caso de hortaliças, o uso de genitores oriundos de germoplasmas com diferentes níveis de resistência à queima-das-folhas não está descartado, pois na exploração de híbridos, com muita frequência, a heterose se manifesta em maior intensidade quando os genitores envolvidos na geração do híbrido possuem maior diversidade genética e os efeitos de dominância são positivos e superiores a zero (Falconer \& Mackay, 1996). Segundo Amorin \& Souza (2005), a divergência genética é fundamental para a exploração da heterose, mas isso nem sempre ocorre.

Embora instalados no mesmo dia e em áreas próximas, o segundo experimento apresentou produção média geral superior ao primeiro $(63,74$ ante 29,45 t/ha). O híbrido Juliana, por exemplo, teve um desempenho muito superior no segundo experimento comparado ao primeiro (17,08 t/ha contra 9,50 t/ha). Essa diferença provavelmente foi influenciada pela maior severidade da queima-das-folhas observada no primeiro experimento, que gerou uma pressão de inóculo muito grande e afetou drasticamente a produção de raízes comerciais, visto que não foi realizada qualquer aplicação de fungicidas para o controle da doença. Um híbrido pode expressar todo seu potencial genético desde que sejam oferecidas condições ideais de manejo. Nesses experimentos, uma possível superioridade desses híbridos de base genética mais ampla foi anulada pela ocorrência da queima-das-folhas, que influenciou na produtividade das parcelas. Outra hipótese provável é que mesmo dentro de uma população, no caso de origem tropical, se consiga gerar linhagens com divergência genética suficiente para que se possam explorar os efeitos heteróticos dos híbridos. Essa hipótese já foi considerada em alguns trabalhos com a cultura do milho (Vasal et al., 1999; Paterniani et al., 2008) e pimentão (Miranda et al., 1988). No caso de cenoura, tal fato possibilitaria desenvolver híbridos altamente resistentes à queima-das-folhas e produtivos, capazes de se adaptar aos mais variados sistemas de cultivo adotados no Brasil.

Diante dos resultados observados, verificou-se que híbridos de cenoura em que ambos os genitores são de origem tropical tendem a produzir híbridos mais tolerantes à queima-das-folhas, e que por meio do cruzamento entre linhagens obtidas de populações de origem tropical e entre linhagens obtidas de populações de origem tropical e temperada, é possível obter híbridos com alta variabilidade e com características agronômicas superiores (produtividade e uniformidade de raízes) às observadas em algumas cultivares de polinização livre, sem prejuízo dos níveis de resistência genética a doenças, como a queima-das-folhas.

\section{REFERÊNCIAS}

ABCSEM - Associação Brasileira do Comércio de Sementes e Mudas. 2009. 10 de outubro. Pesquisa de mercado de sementes de hortaliças. Disponível em http://www.abcsem. com.br/docs/pesquisa_mercado_2009.pdf

AMORIN EP; SOUZA JC. 2005. Híbridos de milho inter e intrapopulacionais obtidos a partir de populações $\mathrm{S}_{0}$ de híbridos simples comerciais. Bragantia 64: 561-567.

ANUÁRIO BRASILEIRO DE HORTALIÇAS. 2012. Brazilian Vegetable Yearbook. Santa Cruz do Sul: Gazeta. 90p

BRITO CH; POZZA EA; JULIATTI FC; LUZ JMQ; PAES JMV. 1997. Resistência de cultivares de cenoura (Daucus carota) a queima das folhas durante o verão. Revista Ceres 44: 371-379.

CRUZ CD. 2006. Programa Genes: estatística experimental e matrizes. Viçosa: UFV. 285p.

EMBRAPA - EMPRESA BRASILEIRA DE PESQUISA AGROPECUARIA. 2012. 15 de setembro. Cenoura Planalto: maior produtividade e qualidade de raiz. Disponível em http://www.cnph.embrapa.br/paginas/ produtos/cultivares/cenoura_planalto.html

FALCONER DS; MACKAY TFC. 1996. Introduction to quantitative genetics. $4 \mathrm{a}$ Edição, Harlow: Longman Group Limited. $464 p$.

HENZ GP; LOPES CA. 2000. Doenças das apiáceas. In: ZAMBOLIN L; VALE FXR; COSTA H (eds). Controle de doenças de plantas: hortaliças. Viçosa: UFV. p. 445-522.

LIMA JÚNIOR JA; PEREIRA GM; GEISENHOFF LO; SILVA WG; VILAS BOAS RC; SOUZA RJ. 2012. Desempenho de cultivares de cenoura em função da água no solo. Revista Brasileira de Engenharia Agrícola e Ambiental 16: 514-520.

MALUF WR; FERREIRA PE; MIRANDA JEC. 1983. Genetic divergence in tomatoes and its relationship with heterosis for yield in $\mathrm{F}_{\mathrm{t}}$ hybrids. Revista Brasileira de Genética 3: 453-468.

MIRANDA JEC; CRUZ CD; COSTA CP. 1988. Predição do comportamento de híbridos de pimentão (Capsicum annuum) pela divergência genética dos progenitores. Revista Brasileira de Genética 11: 929-937.

OLIVEIRA KM; LABORDA PR; GARCIAAAF; ZAGATTOPATERNIANI MEAG; SOUZA AP. 2004. Evaluating genetic relationships between tropical maize inbred lines by means of AFLP profiling. Hereditas 140: 24-33.

OLIVEIRA VR; SCAPIM CA; CASALI VWD. 1998. Diversidade genética e eficiência da predição do comportamento de híbridos de pimentão (Capsicum annuum). Acta Scientiarium 20: 263-267.

PATERNIANI MEAGZ; GUIMARÃES PS; LUDERS RR; GALLO PB; SOUZA AP; LABORDA PR; OLIVEIRA KM. 2008. Capacidade combinatória, divergência genética entre linhagens de milho e correlação com heterose. Bragantia 67: 639-648.

PEREIRA RB; CARVALHO ADF; PINHEIRO JB; SILVA GO; VIEIRA JV. 2012. Resistência de populações de cenoura à queima-das-folhas com diferentes níveis de germoplasma tropical. Horticultura Brasileira 30: 489-493.

PETERSON CE; SIMON PW. 1986. Carrot breeding. In: BASSETT MJ (ed). Breeding vegetable crops. Westport: AVI Publishing. p. 321-356.

SHIBATA ET; REIS A; VIEIRA JV. 2008. Reação de cultivares de cenoura à queima das folhas em campo e a Alternaria dauci em casa-de-vegetação. Boletim de Pesquisa e Desenvolvimento, Brasilia: Embrapa Hortaliças, $14 \mathrm{p}$.

VASAL SK; CORDOVA H; PANDEY S; SRINIVASAN G. 1999. Tropical maize and heterosis. In: COORS JG; PANDEY S. The genetics and exploitation of heterosis in crops. Madison: ASA. p. 363-373.

VIEIRA JV; SILVA GO; CHARCHAR JM; FONSECAMEN; SILVAJBC; NASCIMENTO WM; BOITEUX LS; PINHEIRO JB; REIS A; RESENDE FV; CARVALHO ADF. 2012. BRS Planalto: cultivar de cenoura de polinização aberta para cultivo de verão. Horticultura Brasileira 30: 359-363.

ZERAIK ML; YARIWAKE JH. 2008. Extração de $\beta$-caroteno de cenouras: uma proposta para disciplinas experimentais de química. Química Nova 31: 1259-1262. 